\title{
Cryogenic Damage and Fracture Behaviors of G-11 Woven Glass-Epoxy Laminates*
}

\author{
Kazuaki SANADA** and Yasuhide SHINDO***
}

\begin{abstract}
We discuss the cryogenic damage and fracture behaviors of G-11 woven glass-epoxy laminates. In conjunction with the cryogenic fracture toughness test, a finite element analysis was conducted to predict the fracture and deformation for models of the compact tension (CT) specimens. Effective elastic moduli were determined under the assumption of uniform strain inside the representative volume element. Hoffman's criterion was selected as the criterion for fiber-dominated failure, and matrix cracking was detected by the maximum strain criterion. The virtual crack extension method was adopted to calculate strain energy release rate which leads to determination of stress intensity factor. In order to verify the model, correlations between experimental and analytical results were made, in terms of the load-displacement response and the extent of damage growth. Reasonable agreements between the calculations and the experimental data were achieved.
\end{abstract}

Key Words: Fracture Mechanics, Damage Mechanics, Finite Element Method, Material Testing, Composite Material, Fracture Criterion, Fracture Toughness, Cryomechanics, Compact Tension Specimen, Superconducting Magnet

\section{Introduction}

Due to the attractive combination of mechanical, thermal, and electrical properties, polymeric composites have been used widely for load-bearing structural, thermal and electrical insulation purpose in cryogenic engineering applications such as in the construction of large superconducting magnet systems in the magnetic fusion energy (MFE) generation ${ }^{(1),(2)}$. Additionally, the need for high strength and low weight materials has made polymeric composites ideal for use in aerospace applications, which often require the storage and transportation of cryogenic liquids ${ }^{(3),(4)}$. To ensure their reliability in structural design, it is essential to understand the cryogenic fracture behavior of polymeric composites.

Polymeric composites are often fabricated using a glass fabric reinforcement. These woven composites are more complicated to evaluate than traditional composite

* Received 24th September, 2004 (No. 04-4202)

** Department of Mechanical Systems Engineering, Toyama Prefectural University, 5180 Kurokawa, Kosugi-machi, Toyama 939-0398, Japan.

E-mail: sanada@pu-toyama.ac.jp

*** Department of Materials Processing, Graduate School of Engineering, Tohoku University, 6-6-02 Aoba-yama, Sendai 980-8579, Japan materials because of the interlaced yarns, but there are potential advantages. Some of these are an increased resistance to impact, the ability of "near-net-shape" manufacturing, and resistance to damage, such as delamination ${ }^{(5)}$. Recently, Shindo et al. ${ }^{(6)}$ carried out plane-strain fracture toughness $\left(K_{I C}\right)$ tests with 8 -mm-thick CT specimens at room temperature, liquid nitrogen temperature $(77 \mathrm{~K})$ and liquid helium temperature $(4 \mathrm{~K})$ to evaluate the fracture toughness and the temperature rise of woven glass-epoxy laminates, and studied the damage zone at the notch tip. It was found that the damage zone consists of broken and delamination fiber, fiber pull-out and broken epoxy resin. The presence of the damage can affect the mechanical properties and, subsequently, the response of the composite materials. One of the current major issue in the use of such composite materials is the understanding and prediction of damage modes and failure mechanisms at cryogenic temperatures. A thorough knowledge of the failure mechanisms is bound to lead to the design of efficient and durable structures.

Analytical modeling of damage in composite materials has attracted the attention of researchers. Numerous analytical models have been proposed for analyzing accumulated damage in composite materials ${ }^{(7)-(11)}$. However, the most of the analytical research on woven composites has been focused on predicting the thermo-mechanical 
and thermal properties of woven composites ${ }^{(12)-(14)}$. Attempts to model the strength and associated failure mechanisms are of recent origin. The intricate geometry of the weave combined with geometrical and material irregularity poses a formidable problem in the modeling and analysis of woven composites. Kollegal and Sridharan examined the behavior of a plain weave lamina subjected to compression $^{(15)}$. Chapman and Whitecomb studied progressive damage due to cool-down for plain- and stainweave carbon-carbon woven composite ${ }^{(16)}$. Zako et al. simulated the damage behavior of woven fabric composites by finite element analysis using an anisotropic damage model based on damage mechanics ${ }^{(17)}$.

Dramatic changes in the structure and properties of composite materials can occur when they are exposed to cryogenic temperature. The purpose of this paper is to investigate fracture and damage behaviors in G-11 woven glass-epoxy laminates focusing on the effect of cryogenic temperatures on the failure mechanisms. Fracture toughness tests were performed with CT specimens of different widths and thicknesses at $77 \mathrm{~K}$. The damage zone around the notch tip of tested specimens was characterized using a microscope. A two-dimensional finite element model was also developed to investigate the effect of damage on the specimen response. A micromechanics model is used to predict the elastic properties of G-11 woven glassepoxy laminates. The failure mechanisms of G-11 woven glass-epoxy laminates at cryogenic temperatures can be classified as matrix cracking and fiber-dominated failure (breaking of both fibers and matrix). Two failure modes in the form of matrix cracking and fiber-dominated failure were evaluated using the maximum strain criterion and the Hoffman's criterion, respectively. The validity of the model is demonstrated by the prediction of nonlinear loaddisplacement relation and damage evolution of a CT specimen under fracture toughness tests. The virtual crack extension method was proposed to calculate stress intensity factors.

\section{Experimental Procedures}

\subsection{Materials and specimens}

G-11 woven glass-epoxy laminates were used as specimen materials. The basis for G-11 is the glass fabric of E-glass. Its plain weave is produced by interlacing warp (length) threads ( 43 per $25 \mathrm{~mm}$ ) and fill (width) threads ( 32 per $25 \mathrm{~mm}$ ). The G-11 matrix is a bisphenol-A epoxy resin and the resin weight fraction is $35 \%$.

There are no standard test procedures for evaluating fracture toughness for woven glass-epoxy laminates. Hence, these tests were performed in accordance with the recommendations of ASTM E1820-01 ${ }^{(18)}$ for monolithic metallic materials. Some of the procedures suggested in the above standards may not be directly applicable to woven glass-epoxy laminates. Geometrically similar CT

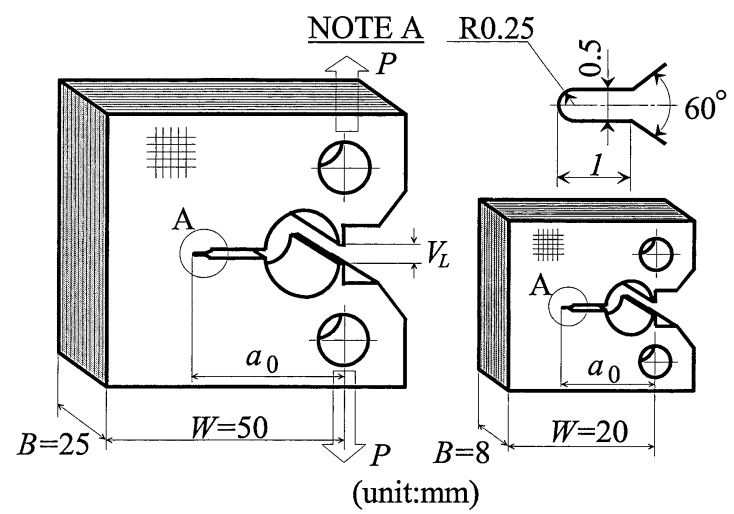

(a) $1 \mathrm{~T}$

(b) $0.32 \mathrm{~T}$

Fig. 1 Geometry of test specimens; (a) 1 TCT specimen, (b) $0.32 \mathrm{TCT}$ specimen

specimens with different widths $(W=20 \mathrm{~mm}, 50 \mathrm{~mm})$ and thicknesses $(B=8 \mathrm{~mm}, 25 \mathrm{~mm})$ were machined from 8 and 25-mm-thick G-11 woven glass-epoxy laminates, and were provided with a lateral notch (initial notch length to specimen width ratio $a_{0} / W=0.5$ and 0.55 ) made by saw. All of them were cut with a sharp fly cutter to give a notch root radius of $0.25 \mathrm{~mm}$. Other specimen features were in accordance with the ASTM E1820-01, except that a modified notch was incorporated. As shown in Fig. 1, the modified notch permits clip gage attachment at knife edges in the loadline. 0.32 TCT specimen ( $W=20 \mathrm{~mm}, B=8 \mathrm{~mm}$ ) and $1 \mathrm{TCT}$ specimen $(W=50 \mathrm{~mm}, B=25 \mathrm{~mm})$ were tested.

\subsection{Testing methods}

Fracture toughness tests were conducted using screw and hydraulic driven testing machines at room temperature and liquid nitrogen temperature $(77 \mathrm{~K})$. The loading rate was kept constant at a crosshead speed of $0.2 \mathrm{~mm} / \mathrm{min}$. For all specimens, the fill fiber bundles were aligned with the load axis. Low temperature environment was achieved by immersing the loading fixture, specimen, and clip gage in liquid nitrogen. During the measurements, load $(P)$ and load-line displacement $\left(V_{L}\right)$ data were automatically logged by computer from a load cell and a clip gage, respectively.

Specimens of G-11 woven glass-epoxy laminates exhibited nonlinear fracture behavior due to damage events at the notch $\operatorname{tip}^{(6)}$. The CT specimens were tested by using the single-specimen unloading compliance technique described in ASTM E1820-01 to determine the $J$-integral versus crack growth resistance curve ( $J-R$ curve) for evaluating the fracture toughness. The compliances were estimated using a linear least-squares best fit to the $P$ versus $V_{L}$ data obtained on unloading. From a crack length $(a)$ versus elastic compliance $(C)$ correlation obtained from finite element calculation, the crack extension increment $(\Delta a)$ at each unloading was inferred. For the CT specimens, values of $J$ are given as

$$
J=J_{e l}+J_{p l}
$$




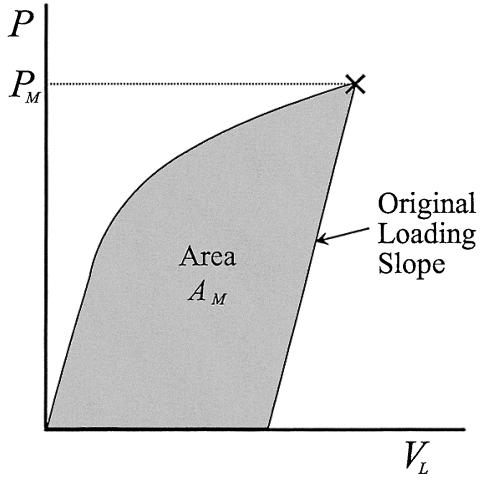

Fig. 2 Definition of area for $J_{C}$ calculation

where $J_{e l}$ is the elastic component of $J$ obtained from finite element calculation and $J_{p l}$ is the plastic component of $J$ obtained by standard procedure ${ }^{(18)}$.

When fracture occurs before stable tearing, the $J$ integral value at the point of crack instability, $J_{C}$, is calculated $^{(18)}$. For the CT specimens, the value of $J_{C}$ is obtained from ASTM E1820-01 as

$$
J_{C}=J_{M}+\frac{\eta_{0} A_{M}}{B b_{0}}
$$

where

$$
\eta_{0}=2+0.522 \frac{b_{0}}{W}
$$

In the above equations, $J_{M}$ is the elastic value of $J$ at the maximum load $P_{M}$ obtained from finite element calculation, $A_{M}$ is the area under the plastic part of the loaddisplacement curve up to the maximum load $P_{M}$ (Fig. 2) and $b_{0}$ is the initial uncracked ligament $\left(b_{0}=W-a_{0}\right)$.

\section{Prediction of Elastic Properties}

A micromechanics model ${ }^{(19)}$ is used to predict the elastic properties of composites reinforced with plain weave fabrics. A representative volume element (RVE) is chosen for analysis and the yarn architecture is described by a few simple functions. These functions are employed to calculate various phase fractions from geometric parameters that can be measured on a cross section. Effective elastic moduli are determined under the assumption of uniform strain inside the representative volume element. Verification of the RVE method for predicting effective elastic moduli for woven glass-epoxy laminates are presented in previous paper ${ }^{(20),(21)}$. The elastic properties of the matrix (epoxy) and fiber (E-glass) were approximated by the exponential functions ${ }^{(22)}$, and the elastic properties of the composite yarns were calculated using equations of Hashin ${ }^{(23)}$. The effective stiffness of the laminates is obtained simply as a volume average of the local stiffness field. The generalized Hooke's relation between stress and strain for a three-dimensional anisotropic material may be written as
Table 1 Effective stiffness components and predicted elastic

\begin{tabular}{|c|c|c|c|c|c|c|}
\hline Temperature & \multicolumn{2}{|l|}{ R.T. } & \multicolumn{2}{|l|}{$77 \mathrm{~K}$} & \multicolumn{2}{|l|}{$4 \mathrm{~K}$} \\
\hline \multicolumn{7}{|c|}{ Effective stiffness components } \\
\hline$C_{11}^{*} \quad(\mathrm{GPa})$ & 28.70 & & 38.35 & & 43.51 & \\
\hline$C_{22}^{*} \quad(\mathrm{GPa})$ & 23.07 & & 33.95 & & 39.76 & \\
\hline$C_{33}^{*} \quad(\mathrm{GPa})$ & 12.12 & & 25.40 & & 32.48 & \\
\hline$C_{12}^{*} \quad(\mathrm{GPa})$ & 4.47 & & 10.01 & & 13.33 & \\
\hline$C_{13}^{*} \quad(\mathrm{GPa})$ & 4.51 & & 10.47 & & 14.05 & \\
\hline$C_{23}^{*} \quad(\mathrm{GPa})$ & 4.55 & & 10.77 & & 14.51 & \\
\hline$C_{44}^{*} \quad(\mathrm{GPa})$ & 5.05 & & 8.53 & & 10.05 & \\
\hline$C_{55}^{*} \quad(\mathrm{GPa})$ & 5.04 & & 8.57 & & 10.09 & \\
\hline$C_{66}^{*} \quad(\mathrm{GPa})$ & 5.17 & & 8.76 & & 10.28 & \\
\hline \multicolumn{7}{|c|}{ Young's moduli } \\
\hline$E_{x} \quad(\mathrm{GPa})$ & 26.66 & $(27.9)$ & 32.98 & $(32.7)$ & 35.94 & $(36.9)$ \\
\hline$E_{y} \quad(\mathrm{GPa})$ & 21.07 & $(24.1)$ & 28.47 & $(31.1)$ & 31.95 & $(34.3)$ \\
\hline$E_{z} \quad(\mathrm{GPa})$ & 10.75 & & 20.48 & & 25.03 & \\
\hline \multicolumn{7}{|l|}{ Shear moduli } \\
\hline$G_{x y} \quad(\mathrm{GPa})$ & 5.17 & $(6.2)$ & 8.76 & $(9.4)$ & 10.28 & $(10.1)$ \\
\hline$G_{y z} \quad(\mathrm{GPa})$ & 5.05 & & 8.53 & & 10.05 & \\
\hline$G_{z x} \quad(\mathrm{GPa})$ & 5.04 & & 8.57 & & 10.09 & \\
\hline \multicolumn{7}{|c|}{ Poisson's ratios } \\
\hline$\nu_{x y}$ & 0.13 & $(0.17)$ & 0.19 & $(0.19)$ & 0.21 & $(0.23)$ \\
\hline$\nu_{y z}$ & 0.34 & & 0.36 & & 0.37 & \\
\hline$\nu_{z x}$ & 0.13 & & 0.21 & & 0.24 & \\
\hline
\end{tabular}
moduli of G-11 at room temperature, $77 \mathrm{~K}$ and $4 \mathrm{~K}$

$$
\left[\begin{array}{l}
\sigma_{x x} \\
\sigma_{y y} \\
\sigma_{z z} \\
\sigma_{y z} \\
\sigma_{z x} \\
\sigma_{x y}
\end{array}\right]=\left[\begin{array}{cccccc}
C_{11}^{*} & C_{12}^{*} & C_{13}^{*} & 0 & 0 & 0 \\
C_{12}^{*} & C_{22}^{*} & C_{23}^{*} & 0 & 0 & 0 \\
C_{13}^{*} & C_{23}^{*} & C_{33}^{*} & 0 & 0 & 0 \\
0 & 0 & 0 & C_{44}^{*} & 0 & 0 \\
0 & 0 & 0 & 0 & C_{55}^{*} & 0 \\
0 & 0 & 0 & 0 & 0 & C_{66}^{*}
\end{array}\right]\left[\begin{array}{c}
\varepsilon_{x x} \\
\varepsilon_{y y} \\
\varepsilon_{z z} \\
2 \varepsilon_{y z} \\
2 \varepsilon_{z x} \\
2 \varepsilon_{x y}
\end{array}\right]
$$

where $\sigma_{x x}, \sigma_{y y}, \sigma_{z z}, \sigma_{y z}=\sigma_{z y}, \sigma_{z x}=\sigma_{x z}, \sigma_{x y}=\sigma_{y x}$ are the stress components and $\varepsilon_{x x}, \varepsilon_{y y}, \varepsilon_{z z}, \varepsilon_{y z}=\varepsilon_{z y}, \varepsilon_{z x}=\varepsilon_{x z}$, $\varepsilon_{x y}=\varepsilon_{y x}$ are the strain components, and $C_{i j}^{*}(i, j=1, \ldots, 6)$ are the effective stiffness components. The effective stiffness components of G-11 calculated from the representative volume element and predicted elastic moduli along with experimental data are listed in Table 1. $\left(E_{x}, E_{y}, E_{z}\right)$ are the tensile moduli, $\left(G_{x y}, G_{y z}, G_{z x}\right)$ are the shear moduli, $\left(v_{x y}, v_{y z}, v_{z x}\right)$ are the Poisson's ratios and figures in brackets indicate the experimental data. The subscripts $x, y$, and $z$ will be used to refer to the coordinate directions, and the Poisson's ratio $v_{x y}$ reflects shrinkage (expansion) in the $y$-direction due to tensile (compressive) stress in the $x$ direction. Also, note that $x, y$ and $z$ coordinates are warp, fill and normal directions, respectively. The tensile moduli $E_{x}, E_{y}$ and the Poisson's ratio $v_{x y}$ were obtained from tensile tests according to JIS K7054 ${ }^{(24)}$. The shear modulus $G_{x y}$ was also obtained from $45^{\circ}$ off-axis tensile tests according to JIS K7059(25). The predicted elastic moduli agree well with the experimental data. 


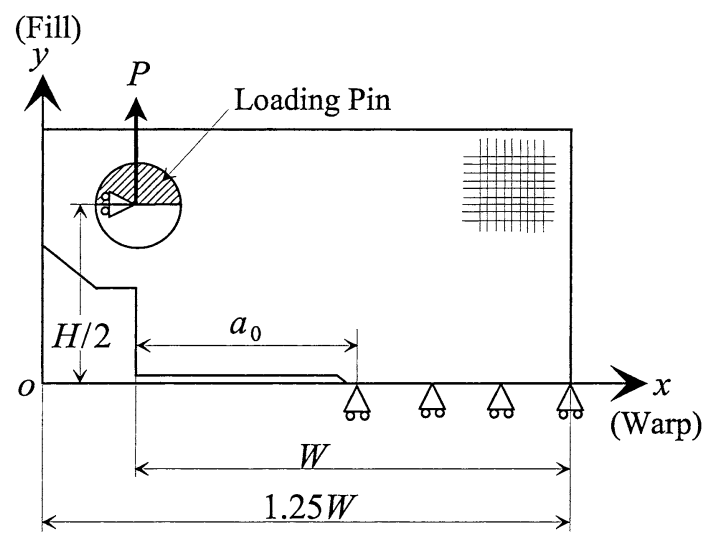

Fig. 3 Boundary conditions assumed for finite element calculations

\section{Finite Element Analysis}

\section{1 Finite-element modeling and boundary condi- tions}

To understand the cryogenic fracture and damage behaviors of G-11, a nonlinear analysis was performed using two-dimensional (2-D) finite element models. In the case of the 2-D computations, the boundary conditions of the 0.32 TCT specimen (the width, $W=20 \mathrm{~mm}$, the thickness, $B=8 \mathrm{~mm})$ and $1 \mathrm{TCT}$ specimen $(W=50 \mathrm{~mm}, B=25 \mathrm{~mm})$ are shown in Fig. 3. $H$ and $a_{0}$ denote the distance between two centers of the loading holes and the notch length, respectively. For the evaluation of elastic compliance and mode I strain energy release rate, a sharp crack was used to model the initial notch in CT specimens. Only one half of the specimen need to be analyzed due to symmetry. The loading pin is modeled as steel. Perfect bonding between specimen and loading pin is assumed to make the model simple. A incremental tensile load $P$ was applied to the loading pin up to the maximum load $P_{M}$ of the CT specimens. The following displacement boundary conditions were applied to the CT specimen.

$$
\begin{array}{lll}
\text { on plane } & y=0 & u_{y}=0 \\
\text { at } & x=0.25 W, y=H / 2 & u_{x}=0
\end{array}
$$

where $u_{x}$ and $u_{y}$ are the displacement components. These assumptions are consistent with the experiment. The finite element mesh is composed of 3324-3 816 six-node triangular elements. The 2-D computations were conducted with either a plane strain or plane stress assumption.

\subsection{Damage growth prediction}

The finite element analysis in this paper consists of a stress analysis and a failure analysis. Stresses and strains in the CT specimens were calculated by a nonlinear finite element analysis. The failure analysis consists of a set of failure criteria and property degradation models. The incremental step method for nonlinear analysis is a stepby-step procedure, where the effect of damage on the mechanical properties are determined at the end of each step,
Table 2 Strains at the knee of G-11

\begin{tabular}{lll}
\hline Temperature & $77 \mathrm{~K}$ & $4 \mathrm{~K}$ \\
\hline Warp & & \\
$\varepsilon_{w}^{0} \quad(\%)$ & 0.83 & 0.76 \\
Fill & & \\
$\varepsilon_{f}^{0} \quad(\%)$ & 0.73 & 0.65 \\
$\pm 45^{\circ}$ off-axis & & \\
$\varepsilon_{s}^{0} \quad(\%)$ & 1.26 & 1.23 \\
\hline
\end{tabular}

and substituted into the next step, thus making the analysis linear over each step. Stresses and strains were calculated at each incremental step, and evaluated by the failure criteria to determine the occurrence of failure and the mode of failure. Mechanical properties in the damaged element are reduced appropriately according to the property degradation models. This process is continued until the desired load (maximum load $P_{M}$ ) is reached. The loading procedure proposed by Yamada ${ }^{(26)}$ was divided into 160-1626 load steps. This procedure used the small and varying increments of load sufficient to just cause failure in the successive elements.

"Knee behavior" of woven composites is a phenomenon by which the stress-strain curve exhibits a knee or change in slope when the composite is subjected to an extensional in-plane load. The knee at cryogenic temperatures is caused by progressive failure of the epoxy resin (matrix $)^{(27)}$. Matrix cracking failure is predicted when the following maximum strain criteria are satisfied.

$$
\begin{aligned}
& \varepsilon_{x x} \geq \varepsilon_{w}^{0} \\
& \varepsilon_{y y} \geq \varepsilon_{f}^{0} \\
& \left|2 \varepsilon_{x y}\right| \geq \varepsilon_{s}^{0}
\end{aligned}
$$

where $\varepsilon_{w}^{0}, \varepsilon_{f}^{0}$ and $\varepsilon_{s}^{0}$ are the strains that locates the knee in the stress-strain curve of G-11 woven glass-epoxy laminates subjected to an in-plane tensile or shear load. The measured $\varepsilon_{w}^{0}, \varepsilon_{f}^{0}$ and $\varepsilon_{s}^{0}$ of G-11 at $77 \mathrm{~K}$ and $4 \mathrm{~K}$ are presented in Table 2. At room temperature, bimodulus behavior does not exist.

For matrix cracking, the tensile and shear moduli and Poisson's ratio of epoxy are reduced as follows.

$$
\begin{aligned}
E_{M}^{d} & =\frac{E_{M}}{10000} \\
v_{M}^{d} & =0.0 \\
G_{M}^{d} & =\frac{E_{M}^{d}}{2\left(1+v_{M}^{d}\right)}
\end{aligned}
$$

where $E_{M}, E_{M}^{d}, G_{M}^{d}$ and $v_{M}^{d}$ are the tensile modulus of epoxy, and the reduced tensile and shear moduli and Poisson's ratio of epoxy, respectively. Effective elastic properties within the damage element were recalculated using the reduced tensile and shear moduli and Poisson's ratio of epoxy. 
Table 3 Mechanical properties of G-11

\begin{tabular}{llll}
\hline Temperature & R.T. & $77 \mathrm{~K}$ & $4 \mathrm{~K}$ \\
\hline \multicolumn{4}{l}{ Tensile strengths } \\
$F_{t x} \quad(\mathrm{MPa})$ & 325 & 656 & 668 \\
$F_{t y} \quad(\mathrm{MPa})$ & 273 & 507 & 506 \\
$F_{t z} \quad(\mathrm{MPa})$ & $272\left(F_{c z} / 2\right)$ & $456\left(F_{c z} / 2\right)$ & $502\left(F_{c z} / 2\right)$ \\
Compressive strengths & & \\
$F_{c x} \quad(\mathrm{MPa})$ & 332 & 660 & 699 \\
$F_{c y} \quad(\mathrm{MPa})$ & 331 & 642 & 650 \\
$F_{c z} \quad(\mathrm{MPa})$ & 545 & 912 & 1003 \\
Shear strength & & \\
$F_{s x y} \quad(\mathrm{MPa})$ & 108 & 147 & 142 \\
\hline
\end{tabular}

The Hoffman's failure criterion ${ }^{(28)}$ was selected as the criterion for fiber-dominated failure. The Hoffman's failure criterion is a supplement to the Tsai-Hill criterion. The linear stress terms account for possible differences in tensile and compressive strengths. For plane stress, the Hoffman's failure criterion becomes

$$
\begin{gathered}
X_{1} \sigma_{y y}^{2}+X_{2} \sigma_{x x}^{2}+X_{3}\left(\sigma_{x x}-\sigma_{y y}\right)^{2} \\
+X_{4} \sigma_{x x}+X_{5} \sigma_{y y}+X_{7} \sigma_{x y}^{2} \geq 1
\end{gathered}
$$

and for plane strain

$$
\begin{gathered}
X_{1}\left(\sigma_{y y}-\sigma_{z z}\right)^{2}+X_{2}\left(\sigma_{z z}-\sigma_{x x}\right)^{2}+X_{3}\left(\sigma_{x x}-\sigma_{y y}\right)^{2} \\
\quad+X_{4} \sigma_{x x}+X_{5} \sigma_{y y}+X_{6} \sigma_{z z}+X_{7} \sigma_{x y}^{2} \geq 1
\end{gathered}
$$

where

$$
\begin{aligned}
& X_{1}=\frac{1}{2}\left[\frac{1}{F_{t y} F_{c y}}+\frac{1}{F_{t z} F_{c z}}-\frac{1}{F_{t x} F_{c x}}\right] \\
& X_{2}=\frac{1}{2}\left[\frac{1}{F_{t z} F_{c z}}+\frac{1}{F_{t x} F_{c x}}-\frac{1}{F_{t y} F_{c y}}\right] \\
& X_{3}=\frac{1}{2}\left[\frac{1}{F_{t x} F_{c x}}+\frac{1}{F_{t y} F_{c y}}-\frac{1}{F_{t z} F_{c z}}\right] \\
& X_{4}=\frac{1}{F_{t x}}-\frac{1}{F_{c x}} \\
& X_{5}=\frac{1}{F_{t y}}-\frac{1}{F_{c y}} \\
& X_{6}=\frac{1}{F_{t z}}-\frac{1}{F_{c z}} \\
& X_{7}=\left(\frac{1}{F_{s x y}}\right)^{2}
\end{aligned}
$$

In the above expressions, $F_{t x}, F_{t y}, F_{t z}, F_{c x}, F_{c y}, F_{c z}, F_{s x y}$ are the three uniaxial tensile strengths, the three uniaxial compressive strengths and the shear strength, respectively. The strengths used for the analysis are presented in Table 3. The strengths $F_{t x}, F_{t y}, F_{s x y}$ were obtained from tensile tests according to JIS K7054 and JIS K7059. The strengths $F_{c x}, F_{c y}, F_{c z}$ were also obtained from compression tests according to JIS K6911 ${ }^{(29)}$. The strength $F_{t z}$ is assumed to be $0.5 F_{c z}$.

For fiber-dominated failure, the tensile and shear moduli and Poisson's ratio of epoxy and fiber are reduced as follows.

$$
\begin{aligned}
E_{F}^{d} & =\frac{E_{F}}{10000} \\
v_{F}^{d} & =0.0 \\
G_{F}^{d} & =\frac{E_{F}^{d}}{2\left(1+v_{F}^{d}\right)} \\
E_{M}^{d} & =\frac{E_{M}}{10000} \\
v_{M}^{d} & =0.0 \\
G_{M}^{d} & =\frac{E_{M}^{d}}{2\left(1+v_{M}^{d}\right)}
\end{aligned}
$$

where $E_{F}, E_{F}^{d}, G_{F}^{d}$ and $v_{F}^{d}$ are the tensile modulus of fiber, and the reduced tensile and shear moduli and Poisson's ratio of fiber, respectively. Effective elastic properties within the damage element were recalculated using the reduced tensile and shear moduli and Poisson's ratios of epoxy and fiber.

\subsection{Strain energy release rate and stress intensity factor}

A two-dimensional finite element analysis was conducted to calculate the stress intensity factor. Sih et al. ${ }^{(30)}$ presented the relationship between stress intensity factor $K$ and strain energy release rate $\mathcal{G}$ for anisotropic bodies: for the special case of orthotropy, with the crack surface parallel to the first principal direction of material properties, the relationship for mode I was given by

$$
K_{I}=\sqrt{G_{I} E^{\prime}}
$$

where

$$
E^{\prime}=\sqrt{\frac{2}{S_{11} S_{22}}}\left(\sqrt{\frac{S_{22}}{S_{11}}}+\frac{2 S_{12}+S_{66}}{2 S_{11}}\right)^{-1 / 2}
$$

In this expression, $S_{i j}(i, j=1,2,6)$ are the elastic compliances. Note that the coordinates $x, y$ and $z$ coincide with principal material directions of the orthotropic material. The two-dimensional strain-stress relationship may be written as

$$
\left[\begin{array}{c}
\varepsilon_{x x} \\
\varepsilon_{y y} \\
2 \varepsilon_{x y}
\end{array}\right]=\left[\begin{array}{ccc}
S_{11} & S_{12} & 0 \\
S_{21} & S_{22} & 0 \\
0 & 0 & S_{66}
\end{array}\right]\left\{\begin{array}{l}
\sigma_{x x} \\
\sigma_{y y} \\
\sigma_{x y}
\end{array}\right\}
$$

The virtual crack extension method proposed by LeNgoc and McCallion ${ }^{(31)}$ is to calculate the total strain energy, $\Pi_{0}$ for the initial crack system, and then move the node at the crack tip by an amount $\Delta a^{*}$ and recompute the total strain energy for the extended crack system, $\Pi_{1}$. The displacements on the externally loaded boundary found for the initial crack length $a^{*}$ are held unchanged while the length is extended to $a^{*}+\Delta a^{*}$. The strain energy release rate can then be approximated by

$$
\mathcal{G}=-\frac{1}{B} \frac{\Pi_{1}-\Pi_{0}}{\Delta a^{*}}
$$

Equation (31) can then be used to calculate the stress intensity factor. 


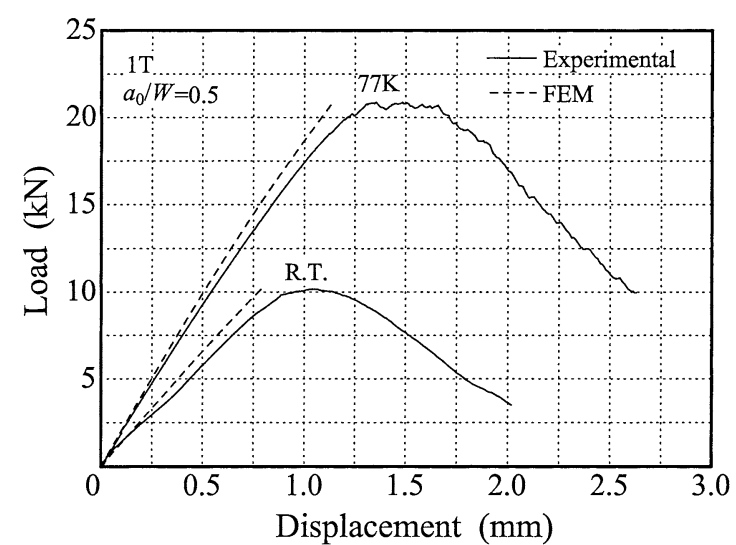

Fig. 4 Comparison between predictions and experiments on load-displacement curves at room temperature and $77 \mathrm{~K}$ for $a_{0} / W=0.5(1 \mathrm{~T})$

\section{Results and Discussion}

\subsection{Load-displacement curves}

In order to verify the proposed model, the predictions were compared with the test data. A 2-D plane strain model of 1 TCT specimens will be studied first to highlight the effect of damage on load-displacement response. 1 TCT specimens were tested to failure without unloadings, measuring load-displacement response. Figure 4 presents the comparison between the measured (solid lines) and the calculated (dashed lines) load-displacement curves at room temperature and $77 \mathrm{~K}$ for $a_{0} / W=0.5$. It is evident that the prediction is relatively close to the experiment up to about $0.2 \mathrm{~mm}$ displacements, but it deviates slightly for large displacements. Similar results were found for the analysis of 0.32 TCT specimens.

The tests conducted to obtain $J-R$ curves were done using an unloading compliance technique. Representative load-displacement curves from unloading compliance tests are shown in Fig. 5. For the 0.32 TCT specimens, the failures of the specimens were catastrophic (dynamic), and occurred shortly after the maximum load. For the 1 TCT specimens, fracture progresses by a series of instabilities. At each unloading point, the instantaneous $J$ and crack length were calculated.

\subsection{Damage progression}

The load-displacement curves are initially linear but deviate progressively from linearity as the slow crack growth or damage occurs in the region ahead of the notch tip. In order to characterize the damage zone produced in front of the notch root during loading, several specimens were unloaded before the final unstable fracture occurred. The notched roots of $0.32 \mathrm{~T}$ and $1 \mathrm{TCT}$ specimens were examined under a microscope. Figure 6 shows a photograph of a 0.32 TCT specimen after loaded to $1.49 \mathrm{kN}$ at room temperature. The crack growth is a simple extension of the notch root. Figure 7 shows the damage near

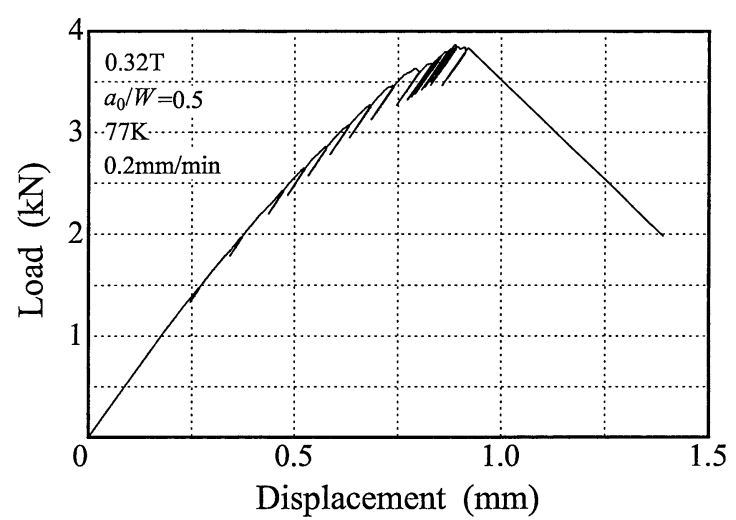

(a) $0.32 \mathrm{~T}$

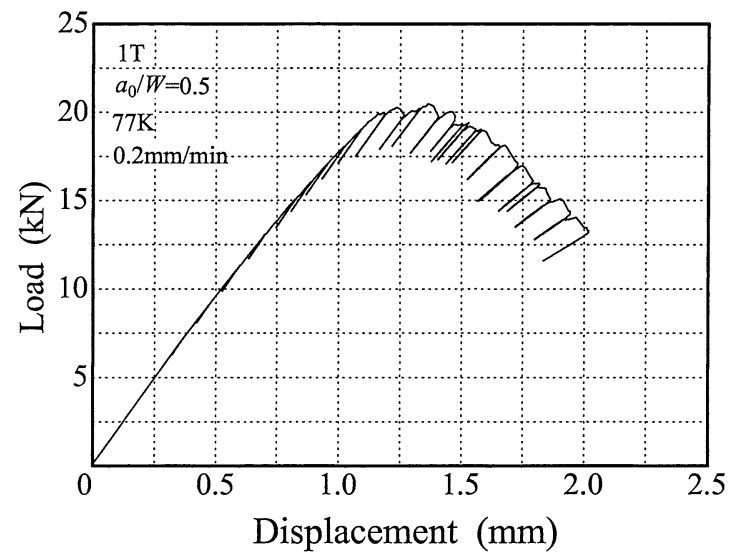

(b) $1 \mathrm{~T}$

Fig. 5 Load-displacement curves for $0.32 \mathrm{~T}$ and $1 \mathrm{TCT}$ specimens

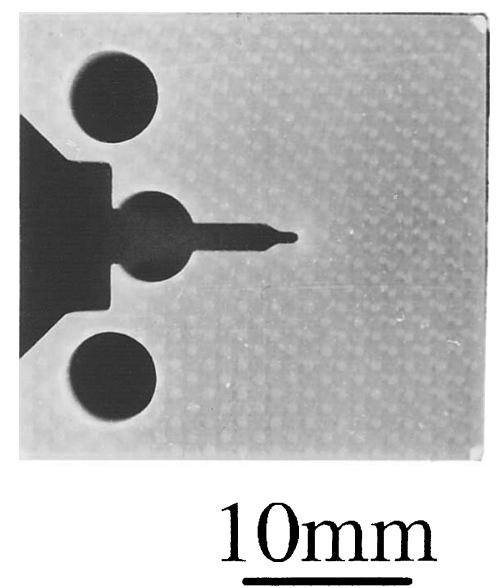

Fig. 6 A photograph of a 0.32 TCT specimen with $a_{0} / W=0.5$ at room temperature after loaded to $1.49 \mathrm{kN}$

the notch tip at $77 \mathrm{~K}$ after the specimens were loaded to some stress levels. A substantial amount of damage can occur as the load is increased. This may be attributed to the brittleness of the epoxy resin, leading to matrix cracking. Figure 8 shows a photograph of a 1 TCT specimen after loaded to $17.40 \mathrm{kN}$ at $77 \mathrm{~K}$.

To further validate the model, the predicted damage progressions of the 2-D plane stress model are exam- 


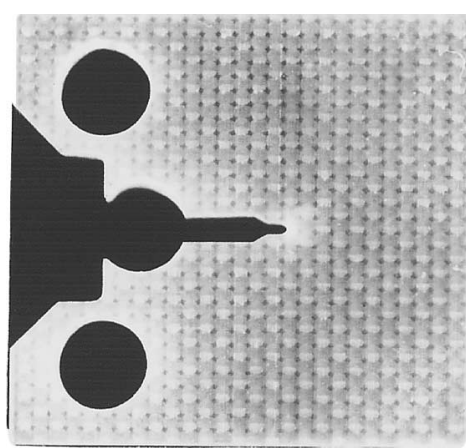

(a) $2.55 \mathrm{kN}$

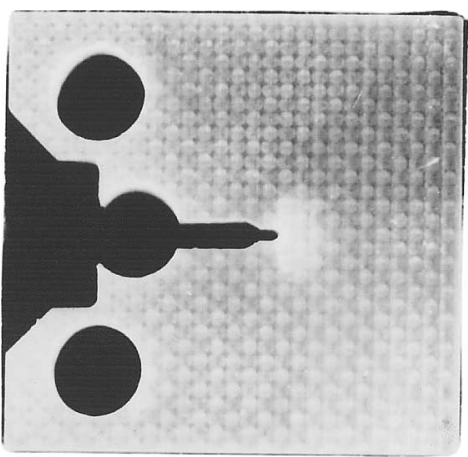

(b) $3.53 \mathrm{kN}$

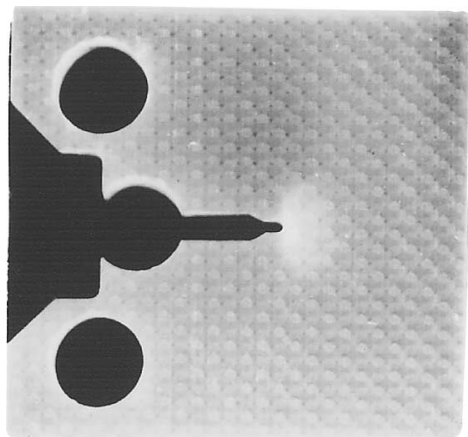

(c) $3.73 \mathrm{kN}$

Fig. 7 Photographs of 0.32 TCT specimens with $a_{0} / W=0.5$ fractured at $77 \mathrm{~K}$ for various loading levels: (a) $2.55 \mathrm{kN}$; (b) $3.53 \mathrm{kN}$; and (c) $3.73 \mathrm{kN}$

ined using the experimental data. Figure 9 presents the predicted damage progression in 0.32 TCT specimens at room temperature and $77 \mathrm{~K}$ as a function of the applied load. The measured damage area was shown by a dotted line. At room temperature, damage initiated from the notch tip, and propagated. The failure mode was dominated by breaking of both fibers and matrix. The damage was confined to area near the notch tip until the load approached the final failure load. The predicted damage pattern in Fig. 9 (a) is qualitatively consistent with the photograph of the damaged specimen in Fig. 6. At $77 \mathrm{~K}$, matrix cracking initiated from the notch tip. As the load level was increased, matrix cracking becomes larger and a smaller number of fiber-dominated failure occur near the notch tip. The size of damage at $77 \mathrm{~K}$ was much more extensive than that predicted at room temperature. The experimental ob-

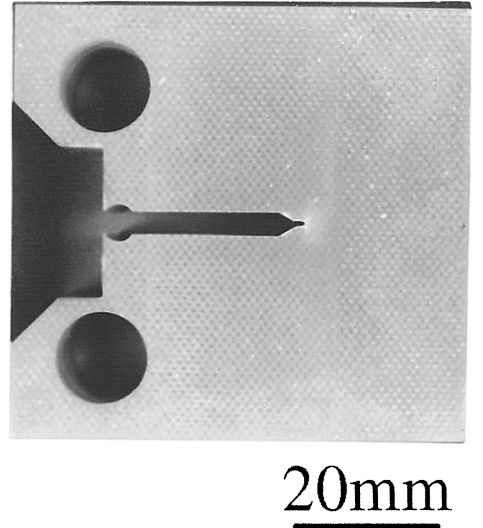

Fig. 8 A photograph of a 1 TCT specimen with $a_{0} / W=0.55$ at $77 \mathrm{~K}$ after loaded to $17.40 \mathrm{kN}$

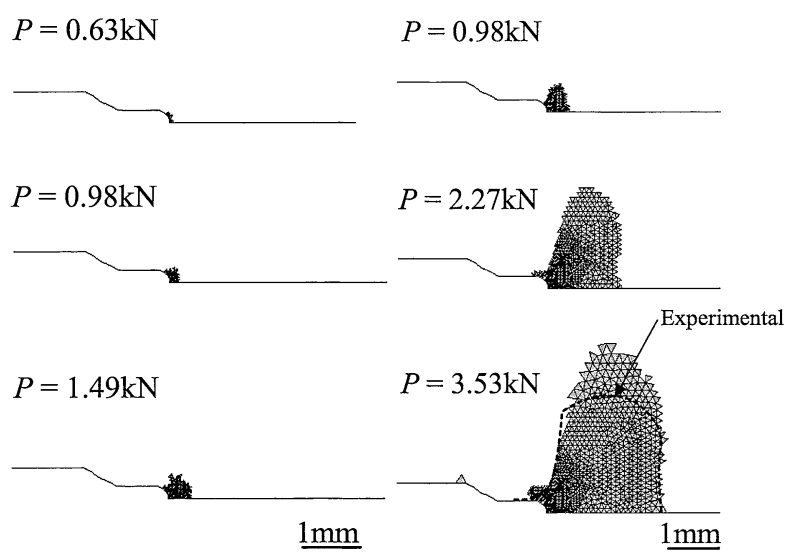

(a) R.T

(b) $77 \mathrm{~K}$

Fig. 9 Illustration of the predicted damage growth pattern in 0.32 TCT specimens with $a_{0} / W=0.5$ as a function of the applied load at (a) room temperature and (b) $77 \mathrm{~K}$

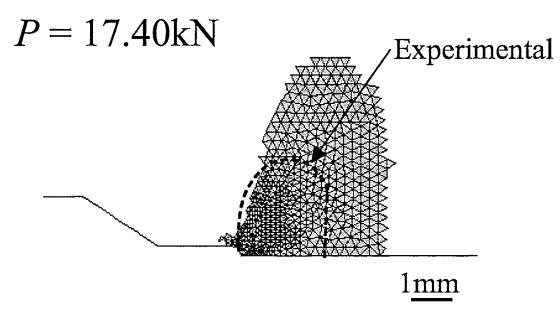

Fig. 10 Illustration of the predicted damage growth pattern in a 1 TCT specimen with $a_{0} / W=0.55$ corresponding to applied load of $17.40 \mathrm{kN}$ at $77 \mathrm{~K}$

servation in Fig. 7 (b) basically agrees with the prediction in Fig. 9(b) expect that the matrix cracking in the fill direction was overestimated. Figure 10 shows the predicted damages of a 1 TCT specimen after loaded to $17.40 \mathrm{kN}$. The measured damage area was shown by a dotted line. At this load, many matrix cracks appear and a smaller number of fiber-dominated failure occur near the notch tip. The predicted damages deviate from the test data.

\subsection{Fracture toughness evaluation}

Using the 2-D plane strain model, computations were 


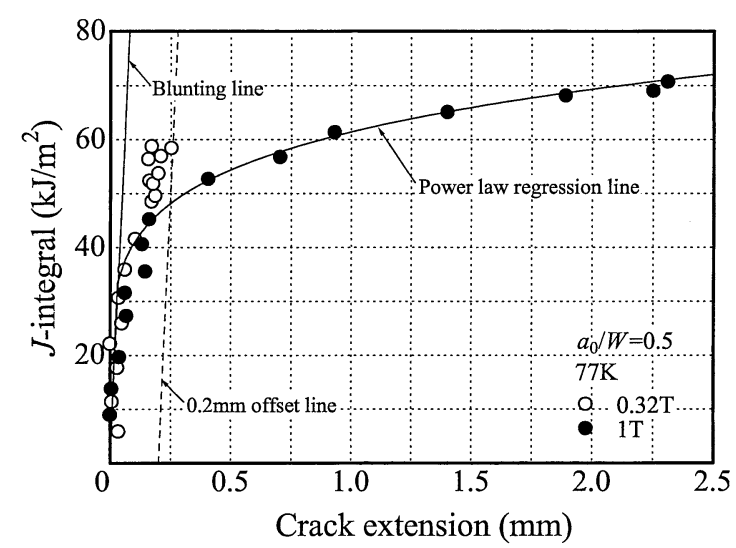

Fig. $11 J-R$ curves at $77 \mathrm{~K}$ for $0.32 \mathrm{~T}$ and $1 \mathrm{TCT}$ specimens

Table $4 \quad J_{Q}$ and $J_{C}$ of G-11

\begin{tabular}{|c|c|c|c|c|c|c|c|}
\hline \multirow{3}{*}{$\begin{array}{l}\text { Temperature } \\
\text { Specimen size } \\
a_{0} / W\end{array}$} & \multicolumn{3}{|c|}{ R.T. } & \multicolumn{4}{|l|}{$77 \mathrm{~K}$} \\
\hline & 0.32 & & $1 \mathrm{~T}$ & $0.32 \mathrm{~T}$ & & & $1 \mathrm{~T}$ \\
\hline & 0.5 & 0.6 & 0.5 & 0.5 & 0.55 & 0.6 & 0.5 \\
\hline$J_{Q} \quad\left(\mathrm{~kJ} / \mathrm{m}^{2}\right)$ & - & - & - & invalid & - & - & 48.0 \\
\hline$J_{C} \quad\left(\mathrm{~kJ} / \mathrm{m}^{2}\right)$ & 15.5 & 17.4 & 21.5 & 46.7 & 47.2 & 41.1 & 60.8 \\
\hline
\end{tabular}

performed to evaluate the fracture toughness. Figure 11 shows the $J-R$ curves for the $0.32 \mathrm{~T}$ and 1 TCT specimens at $77 \mathrm{~K}$. The blunting line, the $0.2 \mathrm{~mm}$ offset line and the power law regression line are superimposed on the plot. The blunting line was determined in accordance with the following equation

$$
J=2 F_{t y} \Delta a
$$

The $J-R$ curves showed significant specimen size dependence. For the $0.32 \mathrm{TCT}$ specimens, final unstable fracture occurs prior to the determination of the required $J$ values versus $\Delta a$ data. For the 1 TCT specimens, the $J$ values versus crack growth behavior is approximated with a best-fit power law relationship. The intersection of the power-law fit with the $0.2 \mathrm{~mm}$ offset line was taken as the $J_{Q}$ value. The $J$-integral results are summarized in Table 4 . Note that the $J_{C}$ values for the 0.32 TCT specimens are calculated from the results of Ref. (6). It is evident from these results that increasing specimen size from $0.32 \mathrm{~T}$ to $1 \mathrm{~T}$ increase $J_{C}$. In the experiments with the $1 \mathrm{TCT}$ specimens it was possible to evaluate the $J_{Q}$ value at $77 \mathrm{~K}$. The $J_{C}$ value for $1 \mathrm{TCT}$ specimen at $77 \mathrm{~K}$ is approximately 1.3 times as large as the $J_{Q}$ value.

The size of predicted damage by fiber-dominated failure of $0.32 \mathrm{TCT}$ specimen at $77 \mathrm{~K}$ as a function of the applied load is shown in Fig. 12. A significant change of slope in the damage size-load relation is observed at a load of $P_{C}$. The $P_{C}$ value seems to be a critical load at which the crack (breaking of both fibers and matrix) initiation and propagation occurs. An apparent fracture toughness $K_{C}$ was calculated for each specimen using the load $P_{C}$. The results of $P_{C}$ and $K_{C}$ of CT specimens with different notch lengths and thicknesses are given in Table 5. It

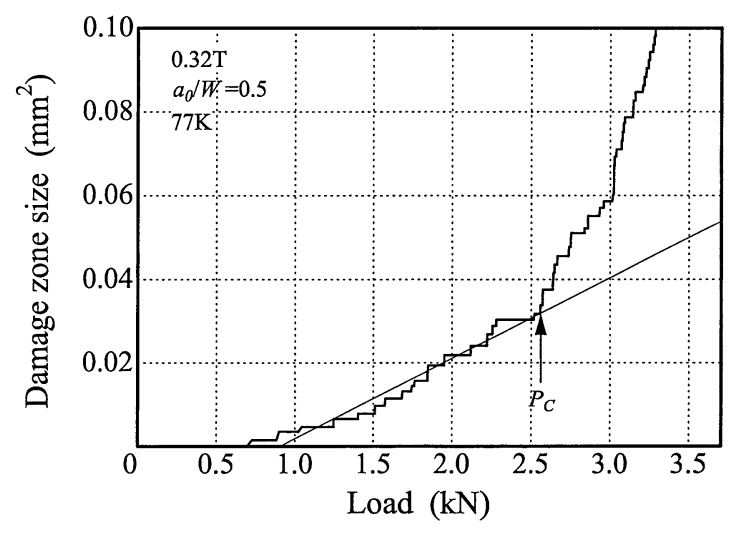

Fig. 12 Variation of damage zone size versus load

Table $5 \quad P_{C}$ and $K_{C}$ of $\mathrm{G}-11$ at $77 \mathrm{~K}$

\begin{tabular}{|c|c|c|c|c|c|}
\hline \multirow{2}{*}{$\begin{array}{l}\text { Specimen size } \\
a_{0} / W\end{array}$} & \multicolumn{3}{|c|}{$0.32 \mathrm{~T}$} & \multicolumn{2}{|l|}{$1 \mathrm{~T}$} \\
\hline & 0.5 & 0.55 & 0.6 & 0.5 & 0.55 \\
\hline$P_{C} \quad(\mathrm{kN})$ & 2.56 & 2.18 & 1.81 & 12.76 & 10.83 \\
\hline$K_{C} \quad(\mathrm{MPa} \sqrt{\mathrm{m}})$ & 21.6 & 21.6 & 21.6 & 21.9 & 21.8 \\
\hline
\end{tabular}

is found that the $K_{C}$ value is independent of notch length and specimen size.

\section{Conclusions}

Cryogenic fracture toughness tests were carried out with $0.32 \mathrm{~T}$ and $1 \mathrm{TCT}$ specimens. An analytical model is also presented for the evaluation of the cryogenic damage and fracture behaviors of G-11 woven glass-epoxy laminates. Based on the study, the following conclusions can be made.

1. The predicted load-displacement curve deviated slightly from the test data.

2. The predicted damage by matrix cracking at $77 \mathrm{~K}$ was overestimated. The size of predicted damage by matrix cracking of the 1 TCT specimen was more extensive than that of the 0.32 TCT specimen.

3. There was significant geometry dependence of the $J-R$ curves at $77 \mathrm{~K}$.

4. The $K_{C}$ value was nearly constant with notch length and specimen size.

\section{References}

( 1 ) Kasen, M.B., MacDonald, G.R., Beekman, D.H., Jr. and Schramm, R.E., Mechanical, Electrical, and Thermal Characterization of G-10CR and G-11CR GlassCloth/Epoxy Laminates between Room Temperature and 4K, Adv. Cryog. Eng., Vol.26 (1980), pp.235-244.

(2) Schutz, J.B., Properties of Composite Materials for Cryogenic Applications, Cryogenics, Vol.38 (1998), pp.3-12.

( 3 ) Timmerman, J.F., Tillman, M.S., Hayes, B.S. and Seferis, J.C., Matrix and Fiber Influence on the Cryogenic Microcracking of Carbon Fiber/Epoxy Composites, Composites: Part A, Vol.33 (2002), pp.323-329.

(4) Bechel, V.T., Fredin, M.B., Donaldson, L., Kim, 
R.Y. and Camping, J.D., Effect of Stacking Sequence on Micro-Cracking in Cryogenically Cycled Carbon/Bismaleimide Composite, Composites: Part A, Vol.34 (2003), pp.663-672.

( 5 ) Kuhn, J.L. and Charalambides, P.G., Elastic Response of Porous Matrix Plain Weave Fabric Composites:Part I-Modeling, J. Compos. Mater., Vol.32, No.16 (1998), pp.1426-1471.

( 6 ) Shindo, Y., Sanada, K. and Horiguchi, K., Fracture Behavior of G-10 Woven Glass-Epoxy Laminates at Low Temperatures, Adv. Cryog. Eng., Vol.42 (A) (1996), pp.129-136.

( 7 ) Chang, K.Y., Liu, S. and Chang, F.K., Damage Tolerance of Laminated Composites Containing an Open Hole and Subjected to Tensile Loadings, J. Compos. Mater., Vol.25 (1991), pp.274-301.

( 8 ) Tan, S.C., A Progressive Failure Model for Composite Laminates Containing Openings, J. Compos. Mater., Vol.25 (1991), pp.556-577.

(9) Shahid, I. and Chang, F.K., Modeling of Accumulated Damage and Failure of Multidirectional Composite Plates Subjected to In-Plane Loads, Composite Materials:Fatigue and Fracture-Fifth Volume, ASTM STP, Vol.1230 (1995), pp.186-214.

(10) Ladeveze, P. and Lubineau, G., On a Damage Mesomodel for Laminates:Micro-Meso Relationship, Possibilities and Limits, Compos. Sci. Tech., Vol.61 (2001), pp.2149-2158.

(11) Zhong, X.A. and Knauss, W.G., Effects of Particle Interaction and Size Variation on Damage Evolution in Filled Elastomers, Mech. Compos. Mater. Struct., Vol.7 (2000), pp.35-53.

(12) Jiang, Y., Tabiei, A. and Simitses, G.J., A Novel Micromechanics-Based Approach to the Derivation of Constitutive Equations for Local/Global Analysis of a Plain-Weave Fabric Composite, Compos. Sci. Tech., Vol.60 (2000), pp.1825-1833.

(13) Dasgupta, A. and Agarwal, R.K., Orthotropic Thermal Conductivity of Plain-Weave Fabric Composites Using a Homogenization Technique, J. Compos. Mater., Vol.26, No.18 (1992), pp.2736-2758.

(14) Dasgupta, A., Agarwal, R.K. and Bhaudarkar, S.M., Three-Dimensional Modeling of Woven-Fabric Composites for Effective Thermo-Mechanical and Thermal Properties, Compos. Sci. Tech., Vol.56 (1996), pp.209223.

(15) Kollegal, M.G. and Sridharan, S., Compressive Behavior of Plain Weave Lamina, J. Compos. Mater., Vol.32, No.15 (1998), pp.1334-1354.

(16) Chapman, C.D. and Whitcomb, J.D., Thermally Induced Damage Initiation and Growth in Plain and Satin Weave Carbon-Carbon Composites, Mech. Compos. Mater. Struct., Vol.7 (2000), pp.177-194.
(17) Zako, M., Uetsuji, Y. and Kurashiki, T., Finite Element Analysis of Damaged Woven Fabric Composite Materials, Compos. Sci. Tech., Vol.63 (2003), pp.507-516.

(18) Standard Test Method for Measurement of Fracture Toughness, ASTM Designation E1820-01, Annual Book of ASTM Standards, American Society for Testing and Materials, Vol.03.01 (2002), pp.1031-1076.

(19) Hahn, H.T. and Pandey, R., A Micromechanics Model for Thermoelastic Properties of Plain Weave Fabric Composites, ASME J. Eng. Mater. Tech., Vol.116 (1994), pp.517-523.

(20) Shindo, Y., Wang, R., Horiguchi, K. and Ueda, S., Theoretical and Experimental Evaluation of DoubleNotch Shear Strength of G-10CR Glass-Cloth/Epoxy Laminates at Cryogenic Temperatures, ASME J. Eng. Mater. Tech., Vol.121, No.3 (1999), pp.367-373.

(21) Shindo, Y., Wang, R. and Horiguchi, K., Analytical and Experimental Studies of Short-Beam Interlaminar Shear Strength of G-10CR Glass-Cloth/Epoxy Laminates at Cryogenic Temperatures, ASME J. Eng. Mater. Tech., Vol.123 (2001), pp.112-118.

(22) Ueda, S. and Shindo, Y., Thermal Singular Stresses and Mechanical Properties in Cracked Glass-Fiber Reinforced Plastics at Low Temperatures, Theor. Appl. Mech., Vol.40 (1991), pp.249-257.

(23) Hashin, Z., Theory of Fiber Reinforced Materials, NASA-CR-1974, NASA Langley Research Center, Hampton, VA, (1972).

(24) JIS K7054-1987, Testing Method for Tensile Properties of Glass Fiber Reinforced Plastics, Japanese Standards Association, (1992).

(25) JIS K7059-1987, Testing Method for In-Plane Shear Properties of Glass Fiber Reinforced Plastics, Japanese Standards Association, (1992).

(26) Yamada, Y., Yoshimura, N. and Sakurai, T., Plastic Stress-Strain Matrix and Its Application for the Solution of Elastic-Plastic Problems by the Finite Element Method, Int. J. Mech. Sci., Vol.10 (1968), pp.343-354.

(27) Kriz, R.D. and Muster, M.J., Materials Studies for Magnetic Fusion Energy Applications at Low Temperatures-VIII, NBSIR 85-3025, National Bureau of Standards, Boulder, Co, (1985), pp.49-86.

(28) Hoffman, O., The Brittle Strength of Orthotropic Materials, J. Compos. Mater., Vol.1 (1967), pp.200-206.

(29) JIS K6911-1979, Testing Methods for Thermosetting Plastics, Japanese Standards Association, (1992).

(30) Sih, G.C., Paris, P.C. and Irwin, G.R., On Cracks in Rectilinearly Anisotropic Bodies, Int. J. Fract. Mech., Vol.1 (1965), pp.189-203.

(31) Le-Ngoc, L. and McCallion, H., On the Fracture Toughness of Orthotropic Materials, Eng. Fract. Mech., Vol.58, No.4 (1997), pp.355-362. 